\title{
ADAPTING CHESS GAME INTO PHYSICAL ACTIVITY IN TEACHING SPEAKING FOR EFL LEARNERS
}

\author{
Armelia Nungki Nurbani \\ Universitas PGRI Adi Buana Surabaya \\ armelianungki@unipasby.ac.id
}

\begin{abstract}
Study of language games has widely spread based on the teachers' experience in facing students' difficulties in speaking English. Colorless speaking activities, fear of making mistakes, and inadequate of mastering vocabularies are some of the causes. Be a creative and innovative teacher is needed to encourage the students to be more active, confident, and enjoy in the class. Game is believed as one of shortcut that used by the teachers which can attract students' attention. Wellchosen game is invaluable to help the teacher in speaking class. This study aims to describe the steps and the implementation of adapted game. Also, investigate the students' perception of adapted game in the EFL speaking classroom. This single descriptive case study was conducted at one of English private courses in Sidoarjo where eighteen Senior High School students in Intermediate level participated as subjects. Interview and class observation were done to eighteen Intermediate students to know their responses regarding to the new adapted game. The finding demonstrated that chess-like game has a great potential to encourage the students' willingness to speak. The students started to talk, feel relax and provoke a lot likewise all along speaking class had alive atmosphere. This study is not only able to illustrate the positive impacts of using adapted game but also add teacher references in adapting various kinds of passive game in their daily live to active game for speaking.
\end{abstract}

Keywords: EFL Speaking class, Adapted game, Chess-like game

\section{INTRODUCTION}

As communicative and interactive activity of teaching and learning process for EFL learners, game is a fun and relax activity used as an educational tool (Wright, 2013). Many educational games are the guidance for encouraging the students to assist their interest. Also, according to Miller (2008), here are some of the reasons why the teacher should use games in teaching and learning process, increasing the students' enthusiasm, bringing a purposeful communication, giving the base of clear input, figuring the variation for learning process, presenting a means to use the English language every time, connecting to all English skills, hooking up to all intelligences (such as interpersonal intelligence, visual intelligence and kinesthetic intelligence).

Conventionally, game is issued for young learners, but factually, it is useful at any stage of education and lesson (Badea, 2015). Using games makes a fun class; the students get attracted and it motivates them to know more and more about new common ideas in language class they have (Amrullah, 2015). Doing games is different from doing assignments in class, which are usually done not only to get prizes, but games are more concerned with the expression of students' ideas. The 
main components in playing a game are goals, rules, challenges, and interactions. Games generally involve mental or physical stimulation, even both.

Allowing what Miller (2008) said that game is an activity that has an aspect for fun, enjoyable and can be used as an educational tool to promote students' willingness to speak. Thus, the teachers can add some tasks of it. Furthermore, game classification is considerably difficult one and it is often overlapped. Hadfield (1999) claimed that there are two sets of language games: (1) competitive games and cooperative games and (2) linguistic games and communicative games. She also backed her argument up that language games contain some technique more than one type in order to have many various activities, for example: sorting game, ordering or arranging game, information gap game, guessing game, searching game, matching game, labelling game, exchanging game, board game, and roleplay game. It is not limited to those examples because games are always innovated diachronically to the development of each era.

Besides that, there are four types of games proposed in this research that can be used by the teacher in augmenting students' English-speaking ability. Those four types of games based on Palanova's thesis (2010), they are listening, speaking, kinetic, and experiential games. Creative English teachers are able to balance serious purpose and entertaining activities in the process of learning especially in speaking class. It is what students sometimes require to have (Palanova, 2010). Therefore, innovative game to make active situation with the same game or method is a decisive topic to discuss here.

Numerous studies have been carried out on the strategies of teachers to teach English speaking, especially the studies of English language game (e.g. Biloon, 2016 and Amrullah, 2015). All those studies' result explained that game is the shortcut way in engaging the students to speak. Biloon (2016) in her study suggested to use games in all language teaching with different type of games. In this case, she suggested four types of game; speaking game with students worked with their small group and discuss a topic, board games are more likely to be applied in English component, board rush is a competition game that included challenge/s in it, and game of charades for movement/physical games. Why the teacher is asked to choose one of those types of games if all four types of games can be put together in a game. Out of the box mind set is needed in every teachers' creativity.

In line with Biloon, Amrullah (2015) agreed that game is a part of language teaching. In his study, he developed 50 language games and categorized to seven types of games, they were Ice-Breakers, Energizers/Warm-Ups, Physical Education Game, Team Building, Problem Solving, Puzzles and Debriefing to teach speaking in one of Senior High School's extra English program. Based on his study's result, most of students prefer to do physical games in speaking class. For example, the game of "What time is it Mr. Wolf?, Who am I?, and Bingo" were the students' favorite games because those provoked concentration and physical action.

One of interesting game to enhance the good atmosphere is chess-like game in speaking teaching-learning. Chess-like game is among them or is not in exception because this game is playing important role to help encourage students to speak and provide a more interactive activity. Chess-like game is a combining game from Biloon's (2016) and Amrullah's (2015) study result. Chess-like game is a speaking game, board game, board rush, and charades or physical or movement game that be put together. Teacher should not be asked to choose one of types of games if several 
possible types of games can be put together in a game. All of teachers, especially English private course can do chess-like game in their speaking class with many different topics, different rules or even any kinds of additions.

Teaching English speaking for EFL especially Indonesian students is significant as a result of the large number of demands of everyone, especially students, to speak English for a communicative purpose globally (Graves, 2008). Cannot be denied that an enormous level of the world's language students study English is to develop their capability in speaking English (Richards and Renandya in Cahyono and Widiati, 2011) but it is not a covert fact that with its earnestness, speaking is precisely alleged to be the most challenging skill for students to master (Oradee, 2012). Moreover, cultural characteristics related to confidence level between English native speaker and Indonesia EFL learners in self-exposition also become bias in the difficult process of English learning. The teachers are less innovative, the students are communally less confidence, and other situations; it all provides monotonous learning process, especially in speaking activity (Goh \& Burns, 2012). As a final point, fear is the utmost reason of Indonesia Students in English speaking. That fear turns anxiety, anxiety turns to mistakes, and mistakes turn to hesitation or the worse, shame is coming, it is the root of mental violence (Hosni, 2014). It is not just about low storage of vocabularies, worse than that; it is the innovation that corrodes the system. In that matter of fact, teaching speaking is considerably a simple process but practically tougher than it seems (Hinkel, 2005).

Since the parents have a high hopefulness and belief in the English private course, the teacher takes an important role to engage the students to have better knowledge of English. So that their children can more quickly and comprehend all English material in school, including the willingness to speak. Same as with Demirtas (2010) study, every private course has different aims but most of them had the aim to support the existing material in formal school. Having speaking class for many private English course teachers is exigently tough because they must afford knowledge for students and develop their speaking skill simultaneously. Teacher should also cultivate, propagate, and drive the students' encouragement to speak (Brown, 2001). Many of students have already stressed full of formal school's activity, time for English private teachers to ponder creatively in elucidating the students' stressfulness. Alternatively, speaking ability in point of fact perhaps completely developed through conversational activities and it encourages the students to create a good interaction in the classroom. Chess-like game takes a part of this, the more supportive and active environment for language learning, the more increased students' willingness to speak. Also, that is not a sort of surprise to manifest a good relationship among teacher and students or students with their friends.

Centered on the explanation above, it is decisive to emphasize that Chesslike game is a meaningful solution to use in speaking class. This study proposes in describing the steps and the implementation of chess-like game in the class. Also, investigating the students' perception of adapted game in the EFL speaking classroom. In this case, it is chess-like game as an adapted game that is used to develop students' willingness to speak. The scope and limitation of this study are limited to the use of chess-like game in speaking class and the material is recount text. 


\section{METHODS}

\section{Study design}

The design of this study came to a case study approach because the result was described based on a person's case and the analysis included (Starman, 2013). Here means that the result was described based on private English course teacher's problem and the fact in the class situation without any manipulation data. Descriptive case study, one of the type of case study was consistent with this current study since the aim was to portray a phenomenon and the real-life setting in which it happened (Yin (2003) in Baxter and Jack (2010)). Also, single case was used in this study as things go scrutinizing the speaking activity deeply in two classes of one English course by applying chess-like game in one or more individuals with the same issue.

\section{Study participants}

Eighteen EFL students of SABB (Sanggar Belajar Bahasa Inggris) English private course participated in this study. The students were from two classes of intermediate level in this English private course and all of them are Senior High students within $10^{\text {th }}$ to $12^{\text {th }}$ grade. The first class consisted of 10 students and the second class consisted of 8 students. The age of the students ranges from 16 to 18 years old.

\section{Data collection}

The data were collected from the students' interview result and class observation. The data were students' point of view about their perception in doing the chess-like game and the interaction in class. In this study, class situation in playing chess-like game was arranged with the help of the teacher. Here were the steps in collecting the data; first, the teachers were introduced by researcher what was chess-like game and taught how to apply. Second, the teachers applied chess-like game in their intermediate classes. The last, the teachers asked some questions as interview. The questions are outlined as follows:

1. Have you ever known this chess-like game before?

2. Did chess-like game give you a new experience?

3. Did the steps and the rules of the game were easy to follow?

4. Did the game encourage you to cooperate with your group in order to win the game?

5. Did the game help you to be more courageous in speaking English?

6. Do you think that speaking with English language is not difficult anymore?

7. Did your speaking class was interactive?

\section{Data analysis}

According to Ellis and Barkhuizen (2005), analysis consists of some procedures, they are identifying, analyzing, and describing the result of the data. After having the data, the researcher started to analyze the data based on Ellis and Barkhuizen's suggestion. Starting from identifying, the researcher identified the answers from the students' interview result by listening the recording. Furthermore, the researcher analyzed and reviewed the identified answers. The last, more detail explanation was shown in order to have complete describing result. 
From chess-like game, it was found out how much this adapted game can be implemented for speaking session with recount text as the material and it can help students in developing their speaking willingness and bringing the benefits and challenges of using adapted game in the EFL class room simultaneously. During the process, the game for this study only used the class' floor without any help of stationery and multimedia tools.

\section{RESULTS AND DISCUSSION}

\section{What chess-like game is and the steps in doing the game}

Chess-like game is an adapted game of chess game, but the differences are in the size, content, hints/rules of play, and amount of the squares. The rules inside are inspired from talking stick; the teacher asked the students to continue the sentence. This chess-like game includes in two sets kinds of language games: the first set is competitive and cooperative games; the second step is linguistic and communicative games.

As a competitive game, the students and their team have to race to be the winner to reach the goal. As cooperative game, the students should team up to win by thinking the best tactic or strategy that fits in it. As linguistic game, this chesslike game focuses on the students' correct sentences in using past tenses. And for the communicative game, chess-like game also focuses on students' correct pronunciation and successful in continuing the sentences. These following are the steps to play chess-like game:

1. First, using the class' floor for the chess board/panel. Do not forget that there are no chairs in chess board, the teacher with the help of students can displace the chairs aside. With the condition of the class floor's squares are not sizable enough, the teacher can make the squares by printed it out as sizable as needed.

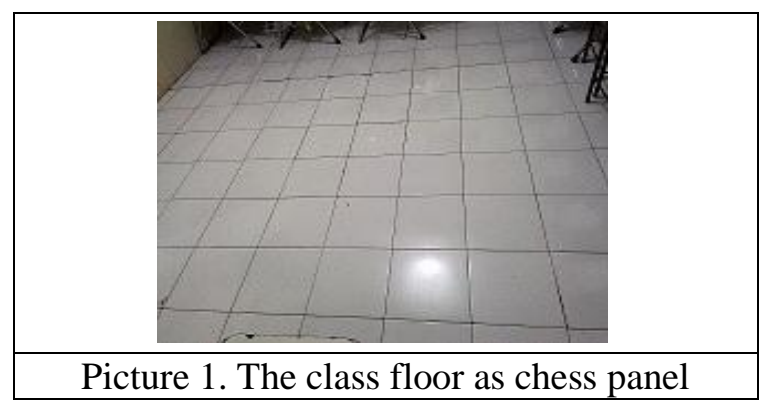

2. Second, organizing the students into two groups; consists of five to seven students in each group. Teacher can divide the students as (s)he wants depends on the total of the students. 


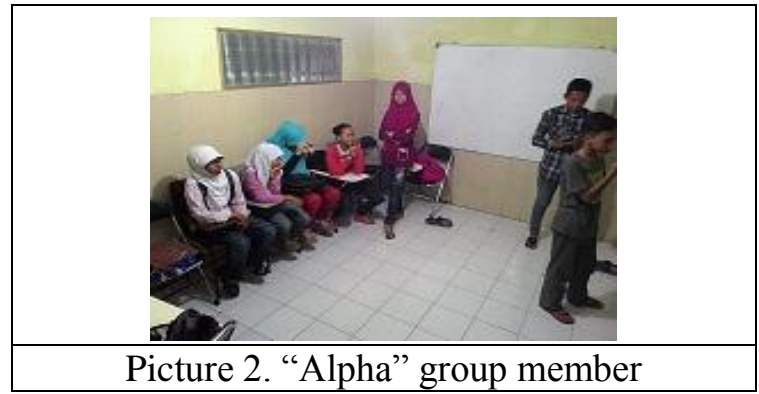

3. Third, determining the maximum of the squares and adding two squares more from the total of students in each group. Here is the example, each group consists of five students, so the squares that are needed $7 \times 7$ is 49 . Teacher can give a line mark with the chairs or others in every corner.

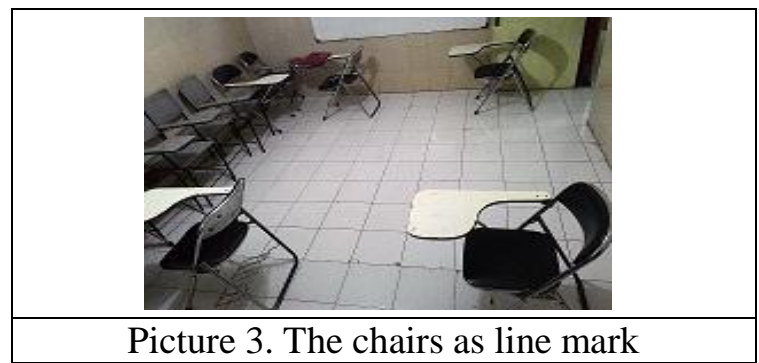

4. Fourth, dividing two groups as a battle group. Asking the students to stand up behind the start line. Meanwhile, please telling them to imagine that they have a castle that should be maintained. All of groups have duties; how their group enter to their enemy's castle and how they can defend to save their own castle. Here, tactics are required.

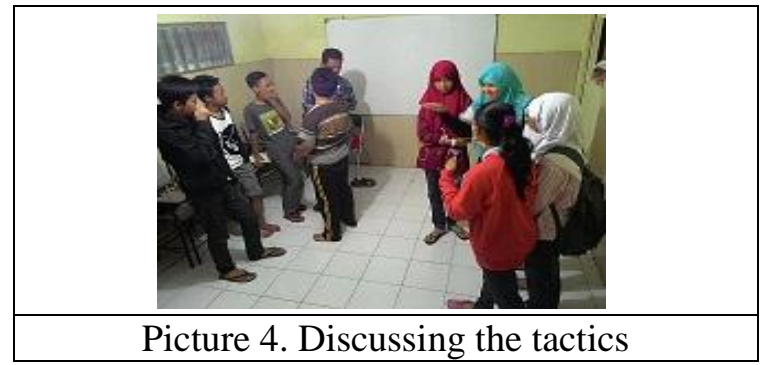

5. Fifth, moving one step for every student. Before, each group has to decide which student as the first stepper, second stepper, third stepper, and so on. In deciding which group as the starter, the leaders have to suit. For each step, each student has to speak directly continuing the sentence from the previous student's. 


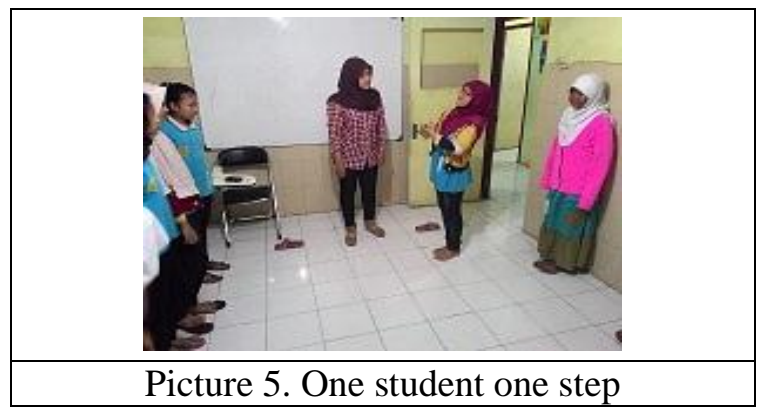

6. Sixth, finishing the step by swapping position (own group then their enemy, back to own group, and so on) until they can arrive and take their enemy's castle. The students are allowed to help their own group members where (s)he has to step and give a clue for the sentence. The students should remember that no sentence no step.

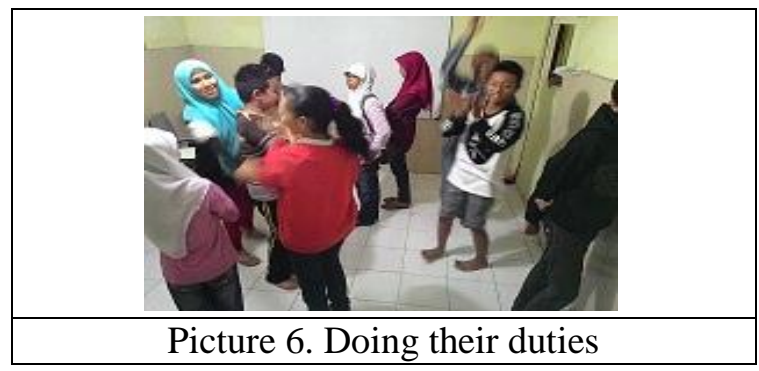

7. Last, paying attention to their enemy's group because all of students are the judges. Wrong sentence is considered as a fault. The group in which all the members can reach their enemy's castle earlier and has lesser fault is the winner.

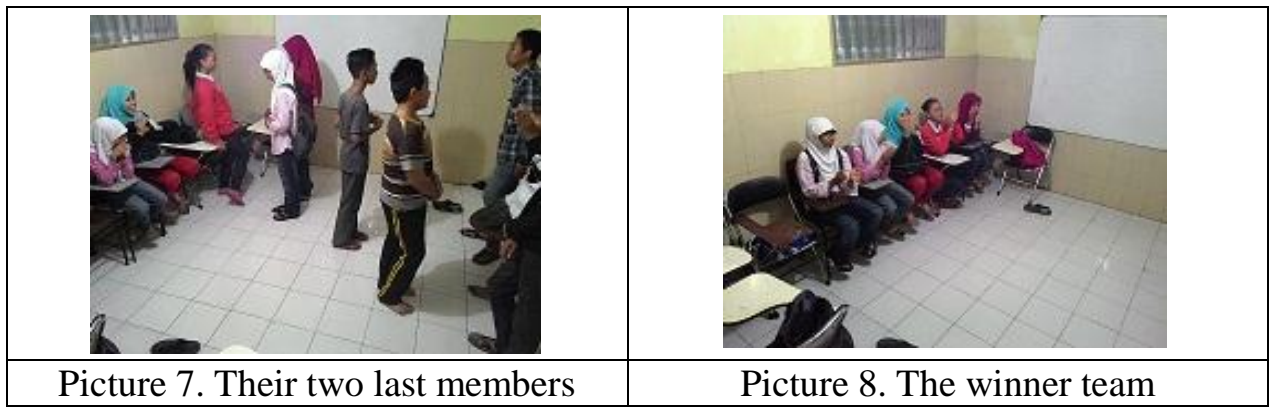

\section{Presenting chess-like game in speaking class}

Many ways in presenting chess-like game for EFL speaking class. Based on Nunan (2003), the teacher can follow the ordinary methodology (pre, whilst, and post-speaking) to teach speaking for EFL students. For pre-speaking phase began with teacher's evoking or conceptualizing to initiate the students' background knowledge. Continuing with the questions which were delivered to the students with the provision of related context between the questions and the topic. The students were given a short story regarding to the topics for making a conclusion of the structure used or the vocabularies. In whilst-speaking phase, the students composed sentences with a fun and pleasant circumstances to check up their 
comprehension. While in post-speaking phase, the teachers did some follow-up activities, like changing the error sentence into the right sentence and giving feedback.

This study proposes one of the helpful strategies for the teachers and students by utilizing chess-like game that can be fascinated learning for all since there is no the most ideal approach to instruct the students for speaking a lot. Before explaining the details about the activities, the researcher took recount text as the example material.

\section{The pre-speaking phase}

Before speaking class, which was running with the chess-like game, here are one of the options and valuable strategies that was applied in this study:

1. Asking a few questions to the students with the related text identified, in this case recount text was applied. The teachers asked the students in reverse with their holiday, absurd, or even scary experience. Not lagging, the teachers asked some questions concerning in what the students are interested in,

2. Giving the students a simple and short story of recount text in a range of five to ten sentences. The story was made by the teachers about someone's experience of seeing miserable accident. Through that miserable story, the teacher gave positive opinions for their students,

3. Requesting the students to read the story anxiously and thoughtfully,

4. Discussing the grammar used in the story with the students. Unconsciously, past tense was taught, and

5. Telling the students if you have a playful game. Explained also to the students for the steps and rules how to play the chess-like game.

\section{The whilst-speaking phase}

Here were the activities in this whilst-speaking that considerably applied:

1. Starting to do chess-like game,

2. Choosing one of the topics that have already prepared by the teachers before. The groups have a same topic. Talking about the topic, the teachers can decide whether (s)he wants to use the same topic or not. For this study, each class only had one pair battle,

3. Asking one of the students for each group be the judge. The duty of the judge was to write the error sentence of their enemy,

4. Making a note from what (s)he hears for students' mistake. Besides that, making a note of students' obstacles when doing chess-like game was needed in order to have better performance for the next, and

5. Shouting hooray if the member of their group has already reached the opposite castle.

\section{The post-speaking phase}

Can be seen as follows, the recommended post-speaking activities:

1. Showing the error sentences of their enemy's group in front of the class. After that, they have to explain why those sentences were error and change into the right sentences,

2. Giving feedback to all the students,

3. Announcing who was the winner in each battle team, and 
4. Giving a special reward to the winner.

\section{Students' perception of chess-like game Students' experience}

From the question number 1, have you ever known this chess-like game before? It is known that all of students have no idea of chess-like game before. From interview result, many of them said that they never know chess-like game, but several students said that they just know chess as a sport.

Student 3 : “Actually, I don't know this game Miss. This is a new game for me. I just know chess as a sport activity"

Student 11: "No Miss, if a chess competition I know, there are the queen, king, horse, army on the chess board"

In line with the class observation, the students answered "haa, what game is that Miss?", "hhmmmm, game baru nih", when their teacher said "ok, enough for the exercise, after this we will play chess-like game".

From those findings, can be seen that teacher can attract the students' curiosity by saying to their students that they will play a new game. Similar with Amrullah's study in 2015 that almost all of students chose a new game which is included in adapt, modify, or invent games as their favorite games and helpful games for speaking. It can give a new input for English private course teachers to always have innovation in presenting a game in the class.

Then, from question number 2 , did chess-like game give you a new experience? Once again, all of students agree that doing chess-like game gave them a new experience even if they have never had it and thought it before because their teachers, both in school and private courses never provide the chess-like game.

Student 1 : "Yes, of course Miss, you know that from this experience in doing this new game, I think I can play this game with my brother in home. We have big floor".

That was also proven by the conversation in the class between teacher and students in the end of the game:

Teacher : "Naahhh, what do you think? The game is cool right?"

Student 3 : "mantap Miss, so cool dah."

Student 18 : "bangeett Miss, I thought that was boring game, only move forward and move forward, but wooooowww ..."

Very clear that with a new game, students get their new experience in teaching and learning process even they can practice the game with their friends in school or with their siblings in home. In line with Nisa's study in 2014, giving a new experience in teaching and learning process with any methodology and activities is needed. From her findings, she revealed that do not only concern in what methodology you used but also the activities in it such as discussion, presentation, simulation, and communication games. So, chess-like game is a good adapted game by concerning on discussion and communication games like what Nisa said.

\section{Steps and rules}

Similarly, concerning with chess-like game's steps and rules in question number 3, all of students agree that the steps and rules are easy to follow because the teachers are asked by the researcher to explain the detail steps and rules with easy example and clear physical demonstrated. 
Student $5 \quad$ : "Yes, I can follow all of the steps and rules' explanation because Miss Vivi practice the steps first"

Student 12 : "Easy sih Miss, but I think Miss Eka too fast in speaking but alhamdulillah I can ask her to repeat and she repeat her demo"

Honestly, there are differences in the way the teachers explained the steps and rules. In the first class, the teacher explained the steps and rules slowly and one by one with physical demonstrated. The teacher often asked "do you get it?" to know the students understanding when she had already explain one step. Same as the teacher in the first class, teacher in the second class demonstrated how the steps were. But the difference was, the teacher of second class explained the steps and rules fluently without delivered the question to check her students understanding. So that's why, many students of the second class gave response like "hah? wait Miss?, explain again Miss".

In Nisa's (2014) study, she concluded that as a teacher we have to have a skill as facilitator to facilitate the students in class especially in giving the explanation. The researcher agreed that the teacher should know what level their students in and how they deal with the way they explain anything. The steps and rules of chess-like game were easy to follow but, back to teachers in explaining.

\section{Benefit for the students' speaking skill}

For the question number 4, did the game encourage you to cooperate with your group in order to win the game? That can be concerned from the students' responses when the teacher asked, "what do you think when you are playing in group and having battle?" and student 1 answered, "I like it Miss, we can talk each other for the tactics and do the game together as a team," continuing with student 2 's answer, "yes Miss, when I confuse to continue the sentence, my friend helped me."

Same as Biloon (2016) study that when a teacher asked the students to speak directly with a topic, many students faced difficulty in answering. But when the students were given opportunity to communicate with their friends, they would be do the best for their speaking. So, grouping is one of the best way to make the students speak.

In addition, in terms of the benefit for the students' speaking skill, almost all the students agreed that chess-like game helped them to be more enthusiastic to speak in English. One of the students said, "tingkat ke-PD an saya kok increase yes Miss" and other student also confirmed that she agreed with her friend "yes Miss, I don't know why suddenly I was so excited and cas cis cus gitu to speak in English". Besides that, more of the half students also agreed that speaking with English is not difficult anymore because their teacher used chess-like game. That can be seen from students' reaction when that was their turn to continue the previous sentence, most of students only need a little time to think and directly speak in English. While the rest said that, "masih lumayan susah sih Miss, because honestly my vocabulary is bad, but I still enjoyed because my team helped me".

\section{Class condition}

Finally, concerning on students' perception in their speaking class condition as the question number 7 , all students agreed that their speaking class was so interactive and strengthened by this conversation below: 


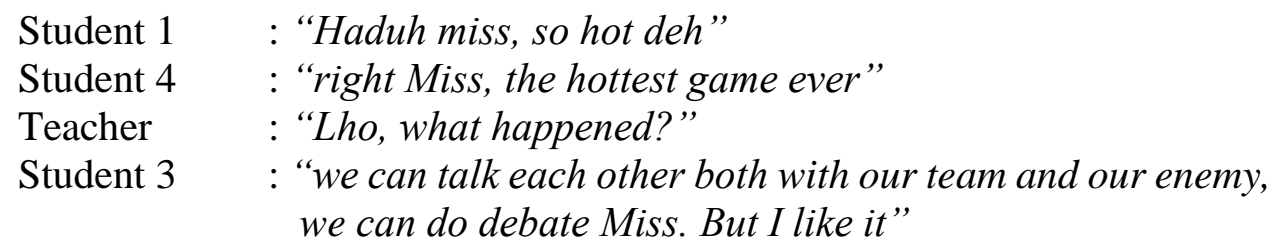

In interview result, there was one student said that one of her friends do not like playing a game or having a group discussion in the class, but that day she enjoyed the game so much.

Students 12 : “you know Miss, usually Rahma doesn't like having a game or grouping. She likes doing everything by herself, but today, she was different Miss. She was very helpful. Please do not say to her ya Miss."

From the evidences above, the students felt "hot" in doing chess-like game. "hot" here means that the students can justify other team if there are mistakes or error sentences beside helped their own team if there are difficulties in making sentence and talked about the tactic. In Devrioka's (2016) study, when the teacher minimized teacher talking time and maximize students talking time, there would be an active class. Extremely agree with Devrioka, it can be seen from class condition when the students did chess-like game, the class so crowded. You will hear 10 and 8 students fully speaking English.

\section{CONCLUSION}

Chess-like game can give numerous preferences for the students. The class atmosphere is no longer teacher centered but the student centered that focus on entire students with no exception. This adapted chess-like game makes a significant setting for teaching speaking with an alternate way. To wrap things up, chess-like game can be utilized to build up the students' willingness, improvement in speaking, and group collaboration. The utilization of chess-like game in the language class can guide the students become progressively dynamic and the students are willing to compete during the English-speaking session.

Since the goal of EFL teaching speaking assists the students with communicative constantly in the target language, teachers ought to give the origin, brand new, and reciprocal language use. For doing those, the teachers should not concentrate on students' fluently in speaking English only, but also concentrates on students' background knowledge, how to fabricate the students' boldness, the students' confidence, and willingness to speak English. In viewing the earlier discussion above and considering the chess-like game attempts those aspects, they are profoundly useful to use in EFL teaching speaking session, especially in English private course.

\section{REFERENCES}

Amrullah, A. Z. 2015. Developing Language Games to Teach Speaking Skill for Indonesian Senior High School Learners. Journal of English Education and Linguistics Studies, 2(2), 13-33.

Badea, M. 2015. English Classes and Effectiveness of Games. Journal Plus Educational technology in HigherEducation, Retrieved on April 9, 2019 at 10.17 a.m. Retrieved from https://www.researchgate.net. 
Baxter, P. E., \& Jack, S. M. 2010. Qualitative Case Study Methodology: Study Design and Implementation for Novice Researcher. The Qualitative Report, 13(4), 544-559.

Biloon, J. S. 2016. Different Reasons to Play Games in an English Language Class. Journal of Education and Training Studies, 5(1), 84-93.

Brown, D. 2001. Teaching by principles: An interactive approach to language pedagogy (2nd ed.). New York: Longman.

Cahyono, B. Y. 2011. The Teaching of English as a Foreign Language in Indonesia. Malang: State University of Malang Press.

Defrioka, A. 2016. The Use of Information Gap Activities in Teaching Speaking (Classroom Action Research at SMK). Lingua Didaktika, Jurnal Bahasa dan Pembelajaran Bahasa, 10(2), 116-126.

Demirtas, H. 2010. The Organizational Commitment and Job Satisfaction among Teachers Working at Private Courses. Inonu University Journal of the Faculty of Education, 11(2), 177-206.

Ellis, Rod. and Barkhuizen, Gary. 2005. Analysing Learner Language. New York: Oxford University Press.

Goh, C. C. M., \& Burns, A. (2012). Teaching Speaking: Holistic Approach. New York: Cambridge University Press.

Graves, K. 2008. The language curriculum: A social contextual perspective. Language Teaching, 41(2), 147-181.

Hadfield, J. 1999. Beginners' communication games. London: Longman.

Hinkel, E. (Ed.). 2005. Handbook of research in second language teaching and learning. New Jersey: Lawrence Erlbaum Associates, Inc.

Hosni, S. A. 2014. Speaking Difficulties Encountered by Young EFL Learners. International Journal on Studies in English Language and Literature, 2(6), 22-30.

Miller, C. T. 2008. Games: Purpose and Potential in Education. New York: Springe Science + Business LLC.

Nisa, S. H. 2014. Classroom Interaction Analysis in Indonesian EFL Speaking Class. Journal of English Education, 2(2), 124-132.

Nunan, D. 2003. Practical Englsh Language Teaching. USA: McGraw-Hill.

Oradee, T. 2012. Developing Speaking Skills Using Three Communicative Activities (Discussion, Problem-Solving, and Role-Playing). An research International Journal of Social Science and Humanity, Vol. 2, No. 6.

Palanova, K. 2010. Use of Games in English Language Teaching. Bachelor Thesis. Masaryk University In Brno. Faculty of Education. Department of English Language and Literature. Brno.

Starman, A. B. (2013). The case study as a type of qualitative research. Journal of Contemporary Educational Studies. 28-43

Wright, A. (2013). RBT: Creating Stories with Children. Oxford University Press. 